Educational Research for Social Change (ERSC)

Volume 10 No. 1 April 2021

pp. 33-51

ersc.nmmu.ac.za

ISSN: 2221-4070

\title{
Finding and Defining Champions in a Rural Adult Education Intervention in Limpopo, South Africa ${ }^{1}$
}

\author{
Rowan Thompson \\ ORCID No: http://orcid.org/0000-0002-9789-9782 \\ Department of Mathematics, Science and Technology, Stadio School of Education \\ rowant@stadio.ac.za
}

\author{
Busisiwe Alant \\ ORCID No: http://orcid.org/0000-0002-9076-210X \\ Science and Technology Education Cluster, School of Education, University of KwaZulu-Natal \\ Alantb@ukzn.ac.za
}

\begin{abstract}
This paper presents the outcomes of a community-based information communications technology (ICT) and basic adult education (BAE) nutrition training intervention for out-ofschool young mothers (YMs) in a resource-limited rural village in eastern Limpopo Province, South Africa. YMs have been identified as a vulnerable and priority group for human development. Out-of-school YMs are often trapped in a cycle of poverty because they lack the resources and qualifications to compete outside their village environment. Implementation of the project's objectives to improve the nutritional and vocational skills education of the YMs was tracked to observe its empowering effect and the effectiveness of the community-based participatory action research (CBPAR) methodology in the implementation of the BAE. Voluntary sampling was used to purposively focus on seven of the 20 selected unemployed YMs between the ages of 18-30 years from this community. The findings revealed that the collaborative CBPAR approach enabled YMs to be empowered in their local community through active participation in the planning, trialling implementation, reflection, observation, and evaluation of the ICT and BAE nutrition course as an out-of-school adult learning experience. During these stages, some YMs displayed what may be considered "champion" behaviours such as higher levels of motivation in class, inviting others to the class, helping peers, regular attendance, and willingness to volunteer locally to access and assist with the facilitation of future courses. This study points to champions acting as catalysts to enable YMs and their older women mentors to fill different roles in the development and delivery of community-based BAE.
\end{abstract}

Key words: basic adult education (BAE), champions, community-based participatory action research (CBPAR), information communications technology (ICT), young mothers (YMs)

1 Ethical clearance number: University of KwaZulu-Natal Research Office EC number: HSS/0573/015M 
Copyright: @ 2021 Thompson and Alant

This is an open access article distributed under the terms of the Creative Commons Attribution NonCommercial License, which permits unrestricted non-commercial use, distribution, and reproduction in any medium, provided the original author and source are credited.

Please reference as: Thompson, R. and Alant, B. (2021). Finding and Defining Champions in a Rural Adult Education Intervention in Limpopo, South Africa. Educational Research for Social Change, 10 (1), 33-51. http://dx.doi.org/10.17159/2221-4070/2021/v10i1a3

\section{Introduction}

This paper reports on a study undertaken in rural Limpopo Province, South Africa, which explored the implementation of an information and communications technology (ICT) and basic adult education (BAE) nutrition course for young mothers (YMs) using a community-based participatory action research (CBPAR) approach (Thompson, 2016). The course attracted 20 unemployed YMs between the ages of 18-30 years from within a resource-limited rural village in eastern Limpopo. Conducting research in remote rural locations in South Africa presents a number of challenges in terms of access, facilitating, and resourcing. Providing adult education to vulnerable groups such as YMs has its own set of challenges, especially when they are inhibited from participating in community events or discouraged from attending courses (Singh \& Naicker, 2019). Locating new training initiatives in settings such as these also reveals the tensions between local and national government, traditional village management structures, and unseen informal networks that operate in such communities.

Defining rurality in the postapartheid context is complex because it requires an understanding of existing sociopolitical tensions relating to land ownership and restitution of human rights and property (Balfour et al., 2011). Boundaries between rural, peri-urban, and urban spaces are being redefined and redrawn as some groups try to protect rural and urban spaces. This has led to inequities in the provision of educational opportunities (Trahar et al., 2020). Provincial towns and cities are experiencing increases in population and strain on municipal resources as unemployed youth "forge new identities" seeking employment, further education, and vocational opportunities (Cuervo, 2016, p. 48). Growth of cities, overcrowding, and pressure on resources are viewed as phenomena of contemporary times. Migration from rural areas is not a modern trend but traceable back to apartheid labour and land expropriation laws and practices (Sikakane, 1977). Settlement in rural villages may be due to tribal history but can equally be ascribed to past forced relocation, as is the case with the families in the village under study.

Populations in rural villages are experiencing a shift in gender bias as educated young women follow men to towns and cities to seek the same opportunities (Statistics South Africa, 2017). The brain drain experienced nationally as graduates leave the country in pursuit of overseas opportunities is also experienced at the rural level. Rural villages have become permanent residences for the marginalised, the elderly, the disabled, and the unemployable. Many of these issues have been exacerbated by the Covid-19 pandemic and subsequent economic recession (United Nations [UN], 2020).

Out-of-school YMs are often trapped in a cycle of poverty because they lack the resources and qualifications to compete outside their village environment (Chase, 2017). Local adult education initiatives can help to alleviate some problems of isolation and lack of exposure to wider opportunities (Jernigan et al., 2015). They can also be viewed as potential opportunities for YMs to lead and innovate within their communities, challenge established patriarchal structures, and drive development through local BAE and entrepreneurship (Vincent, 2016). 
YMs are considered a vulnerable group, globally (UN, 2020). The World Health Organisation (WHO) described vulnerable YMs as those between 18 and 25 years with children under the age of five (YMs younger than 18 are minors and are categorised separately). In rural and remote locations in subSaharan Africa, YMs are sometimes shamed, stigmatised, and ostracised by family members and from social groups (Nkani \& Bhana, 2016). While schools offer some opportunities for return to study after giving birth, they do not allow pregnant learners to remain in school to complete their matric.

Lack of opportunity to experience further education or to return to high school to complete secondary education is not confined to African YMs (Fredman et al., 2016). Single parenthood in conjunction with high unemployment and lack of acceptance in patriarchal rural communities increases the need for adult learning opportunities.

Defining what type of action research (AR) to employ in research contexts has become a subject of academic debate. Lewin's (1951) cyclical AR process provided the structure referred to in most 20th century forms of AR. Habermas (1987) expanded on the themes of participative and communicative action. Schön (1987) personalised research under the themes of reflective practice that relate to selfstudy research. Whitehead (1989) explored improving educational practice through self-reflective questioning. Kemmis et al. (2014) established critical participatory action research (PAR) as a 21 st century composite. Their approach brought together community-based and critical emancipatory approaches where groups reflect on practice and practice architectures within communicative spaces (Kemmis et al., 2014). The study of AR has led to increased awareness that whatever name is used, it should be a social practice that aims to transform practice (Kemmis, 2009).

Researching the implementation of a BAE course involved exploration of AR suited to establishing and implementing practical training outcomes. Collaboration with local community members and structures prior to the course set the scene. Predefined categories of practical AR that are projectbased and self-directed were considered alongside community-based collaborative forms (Kemmis et al., 2014). The research involved direct participation of one of the authors as a researcher, local and volunteer trainers, YMs, and members of the wider community in an attempt to improve the BAE opportunities of out-of-school YMs. A community-based approach to AR was adopted because it draws on participatory themes of reciprocity (Maiter et al., 2008) and shared experience in social spaces (McTaggart, 2002).

This study sought to document, interpret, and understand the implementation as a form of transformative action that was likely to need refining and improvement after the first cycle of delivery. In this regard, CBPAR facilitated the process.

\section{Methodology}

The study sought to answer the following broad question, which was then broken down into three subquestions: "How do we use CBPAR as a basis for a BAE programme to provide out-of-school YMs with effective ICT and nutrition training in a rural area?"

In other words:

- How can a community of practice be established to design and implement an ICT training course that includes BAE nutrition education?

- How can community-based ICT and nutrition training courses for YMs be implemented in rural resource-limited settings such that they are sustainable? 
- How can further constructive interaction be stimulated as part of establishing a process of continual improvement through direct engagement?

Community of practice (CoP) was considered appropriate because one had already been established in a cooperative venture to design and build an adult education centre in the village (see Image 1).

\section{Image 1}

Mulamula Education Centre Project (MECP) Building with Library, Hall, Office, and ICT Teaching Area (source: Thompson, 2016)

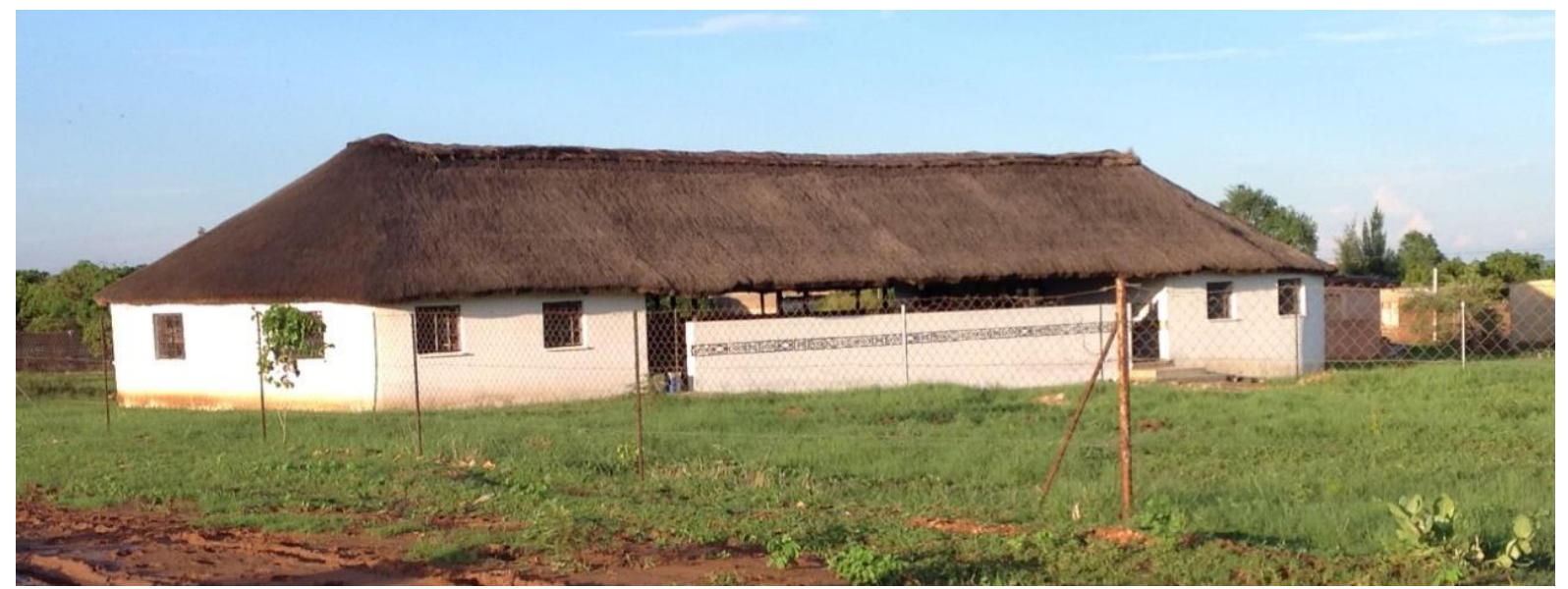

The CBPAR methodology employed in this study was based on a five-phase model, which emerged from the study of PAR methodologies (Kemmis et al., 2014; Kindon et al., 2007; McKay, 2011; Pain et al., 2011). These are commonly employed in capacity building and training as part of healthcare research and community development (Vincent, 2016). The choice of CBPAR was influenced by its attractiveness as an inclusive community-based approach that provides structure to practical interventions in remote resource-limited settings. The CBPAR approach was reinforced by the establishment of a CoP (Lave, 1991; Wenger, 1998) and the use of appreciative inquiry (Cooperrider et al., 2008) methodologies. The latter were used to guide the interpretation and thematic analysis of the data (Saldaña, 2012).

The three main stages of the process-(i) pre-intervention, (ii) implementation, and (iii) postintervention-are presented below. The five-phase model was used to structure the study further and relate the chronological activities to the theoretical elements that were identified as necessary for understanding the process. Following a PAR approach (Maiter et al., 2008) stimulated the adoption of a cyclical reflective model for addressing issues of community reciprocity and recognising YMs' BAE as a process of continual improvement (see Figure 1).

This cyclical or repeating spiral process, common to most forms of $A R$, helped guide the design of the research instruments to show relevance, rigour, and reach (Balazs \& Morello-Frosch, 2013) during key stages of the intervention. These graphical models take inspiration from Kurt Lewin's (1951) representation of $A R$ as a repeating cycle of planning, action, observation, and reevaluation. The graphical interpretation, as illustrated in Figure 1, represents the CBPAR process in this study as an organised cyclical process that, in development terms, reveals future iterations of an intervention or community-based project. 


\section{Figure 1}

CBPAR as a Cyclical Process where Relevance, Rigour, and Reach are Significant Factors (source: Thompson, 2016)

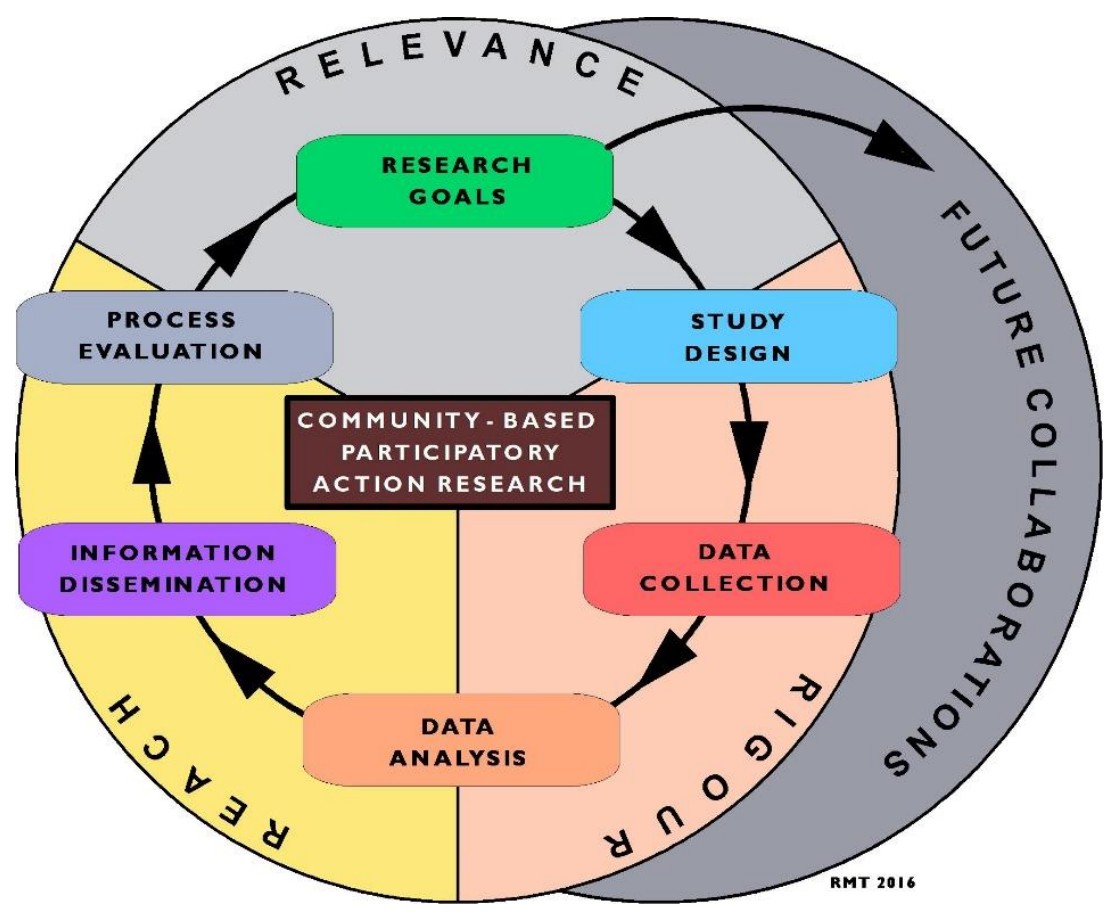

\section{Location}

The study took place in Mulamula village, which lies half an hour's drive east of the town of Elim, and about 20 minutes' drive west of Malamulele town in Vhembe District, Limpopo. Various locations in the village were used to gather the data. These included the traditional council office, the researcher's home, Mulamula Education Centre Project hall (see Image 1), and Mahlefunye Primary School. The main location for the weekly teaching of the YMs' ICT and BAE nutrition course over a period of six weeks was the school computer room. The MECP hall was to become the location for future BAE courses.

Initially, training was to be in the MECP's dedicated ICT room. However, technical delays resulted in the change of venue. The principal of Mahlefunye Primary School, and secretary of the MECP's committee, offered the use of their computer room, which had no computers. The physical organisation of this training area was done voluntarily by the participants.

\section{Ethical Considerations}

Gatekeeper clearance was given by the traditional council office, MECP project committee, and host school in the first instance. Participants followed the consent processes prescribed by the University of KwaZulu-Natal Research Office (EC number: HSS/0573/015M) and recommended in PAR guides (Mckay, 2011; Pain et al., 2011). Additional venue permissions were sought on site with the help of XiTsonga-speaking mediators. 
Informed consent was explained in English and translated verbally into XiTsonga. Participation was completely voluntary. In addition, the participants were informed of their freedom to withdraw from the research at any time and were also guaranteed full anonymity.

The course was delivered after school hours in a secure ICT classroom to ensure that the risk of harm to participants was negligible. Using male trainers required consideration of the potential vulnerability of the YMs (Kaukko, 2016). The primary school's deputy head actively observed training and reported on interactions between trainers and trainees. Trainers used partnered teaching to make sure that YMs were not isolated with any instructor.

\section{Stages of the Process}

A five-phase model was used to structure the research as a CBPAR process:

- Phase 1. Getting stakeholders to agree to the long-term vision of the process.

- Phase 2. Creating infrastructure for a process that fosters participation and engagement.

- Phase 3. Developing community links that sustain commitment from all members.

- Phase 4. Orientating systems to enable the long-term function of the process.

- Phase 5. Pursuing goals that are of value to all stakeholders-following outcomebased advocacy.

To structure the instruments and tools used for the implementation of the study, it was necessary to fit these phases to stages that related to the chronological order of events planned by the researcher and stakeholders. It also enabled the researcher to identify which archived data would be most relevant from the establishment of the CoP through the MECP committee and other meetings.

- Stage 1. Pre-intervention: Establishing a CoP and reaching agreement with stakeholders on achievable goals for the study.

- Stage 2. Implementation: Implementing the study with the support of the participants using systems designed collaboratively to sustain the study.

- Stage 3. Post-intervention: Evaluating the study and discussing results with the participants to establish a roadmap for similar future interventions.

\section{Relating the Stages of the CBPAR Process to the Research Questions and Practical Objectives}

Because the study involved the actual setting up and implementation of a course in a rural village context, the research objectives had to be linked to the stages of setting up, implementing, and evaluating the process. The research questions were aligned to the CBPAR phases. This allowed the results to emerge organically as the implementation proceeded. These interrelationships are presented in Table 1. 
Table 1

Relating the Research Questions to the CBPAR Phases and Objectives

Research Questions Phases of CBPAR Objectives

How do we use CBPAR as a basis for a BAE programme to provide out-of-school YMs with effective ICT and nutrition training in a rural area?

RQ1: How can a community of practice be established to design and implement an ICT training course that includes BAE nutrition education?
1. Getting stakeholders to Build a CoP to deliver the study by establishing agree to a long-term vision. the needs of YMs through direct engagement with the community and planning the delivery with stakeholders - setting the stage for the participation.

2. Creating infrastructure that fosters participation and engagement. using a participatory process that fits the needs
Design a combined ICT and basic nutrition course and aspirations of the participants-YMs - in the village environment.

Design course content in collaboration with local trainers using a simplified end-user computer course structure augmented with basic nutritional content sourced from WHO training materials.

3. Developing community Recruit YMs using different tools. links that sustain commitment from all members.
Enlist the help of volunteers in the local community.

Develop a network of support between the trainer, facilitator, primary school, and volunteers to establish the course practically, and trial the course in advance.

Invite YMs to participate using a communitybased workshop.

Deliver the course with volunteer trainers and facilitators over a 6-week period, monitor participants' progress, and gather data through a variety of tools to monitor effectiveness and establish improvements required.

Evaluate the course with participants to reflect on the process and its effect on them.

Construct practical goals to share with the community-especially the champions from the YMs' group - to help sustain the course in future.
RQ3: How can further constructive interaction be stimulated as part of establishing a process of continual improvement through direct engagement?
5. Pursuing goals that are of value to all stakeholders-following outcome-based advocacy.
4. Orientating systems to sustain the process.

\section{Collection of Data}

Data was collected over the course of six months in the village. The main instruments, or key events that were used to gather the data, are illustrated in Table 2. The focus was to record the participation of the YMs and follow their development through the recording of their own observations and outcomes in the course. This was triangulated using feedback from the trainers and school staff 
involved in facilitating the course, supported by interviews, phone calls, and WhatsApp communication.

\section{Table 2}

Instruments Used in the Study

\begin{tabular}{|c|c|c|c|}
\hline Stage & Pre-Intervention & Implementation & Post-Intervention \\
\hline Instruments & $\begin{array}{l}\text { - } \text { Meetings of MECP } \\
\text { committee } \\
\text { - } \text { Meetings with } \\
\text { stakeholders } \\
\text { - Workshop with YMs and } \\
\text { other participants } \\
\text { - Course design in } \\
\text { collaboration with } \\
\text { volunteers and } \\
\text { participants }\end{array}$ & $\begin{array}{l}\text { - } \text { Course content } \\
\text { - Recruitment forms } \\
\text { - Application forms } \\
\text { - Observations from lessons } \\
\text { - Feedback from lessons } \\
\text { - Class registers }\end{array}$ & $\begin{array}{l}\text { - } \text { Course evaluations } \\
\text { - Structured interviews for } \\
\text { YMs } \\
\text { - Semi-structured interviews } \\
\text { for trainers and other } \\
\text { peripheral participants } \\
\text { - Presentation of data using } \\
\text { graphical diagrams to aid } \\
\text { dissemination and } \\
\text { interpretation of data }\end{array}$ \\
\hline
\end{tabular}

The instruments indicated in Table 2 were used to gather data from the participants who helped to establish the CoP, those who recruited and trained the women, and the YMs themselves. Establishing a CoP required the "reconfiguring of relationships" (Murray \& Rudolph, 2019, p. 24) with village structures, and development of new relationships with stakeholders to avoid the project being treated as an imposed idea from outsiders - as was the trend in the past.

The tools used to collect the biographic data, as well as the qualitative data from the YMs and other key participants, are shown in Table 3. The minutes of meetings, formal letters, and other published documents that were produced are also indicated. This data assisted in establishing the timeline of events from the inception of the project to the conclusion of the YMs' course.

\section{Table 3}

\section{Tools Used in the Study}

\begin{tabular}{|c|c|c|c|}
\hline Stage & Pre-Intervention & Implementation & Post-Intervention \\
\hline Tools & $\begin{array}{l}\text { - } \text { Minutes } \\
\text { - } \text { Newsletters } \\
\text { - } \text { petters of } \\
\text { - Text mission } \\
\text { conversations }\end{array}$ & $\begin{array}{l}\text { - } \text { Course resources } \\
\text { - Structured forms } \\
\text { - } \text { Questionnaires } \\
\text { - Video and photography* } \\
\text { - Semi-structured interviews via Skype** } \\
\text { - Text messaging conversations }\end{array}$ & $\begin{array}{ll}\text { - } & \text { Evaluation forms } \\
\text { - Structured interview } & \text { schedule } \\
\text { - } & \text { Text messaging } \\
\text { conversations } \\
\text { - } \\
\text { Computer-aided } \\
\text { design software to } \\
\text { illustrate the results }\end{array}$ \\
\hline
\end{tabular}

\footnotetext{
* Video recordings and photographs of lessons were used but the results are not discussed in this paper.

**Interviews were recorded using two voice recorders recording simultaneously.
}

Tools were designed to help triangulate and interpret information from different participants or sources in the day-to-day progression of the course. Text messaging via the WhatsApp mobile messaging service was used for eliciting rapid feedback from the participants. This form of 
instantaneous communication assisted with the remote management of the study and with supporting volunteers on the ground.

\section{Study Sample}

Voluntary sampling was used. Twenty YMs attended the ICT-BAE nutrition course. All were from Mulamula village. The focus of analysis fell purposefully on seven out-of-school YMs in the age range of 18-25 years with a child younger than five years old. YMs in this group were considered vulnerable because, at the time, schools were not obliged to take students of adult age back to complete their studies. This produced a representative sample of the group (35\%). Figure 2 illustrates the interrelationship between the YMs, trainers, and other local participants.

\section{Figure 2}

\section{Diagrammatic Model Indicating Core Contributors in the CBPAR Intervention With YMs at the Centre (source: Thompson, 2016)}

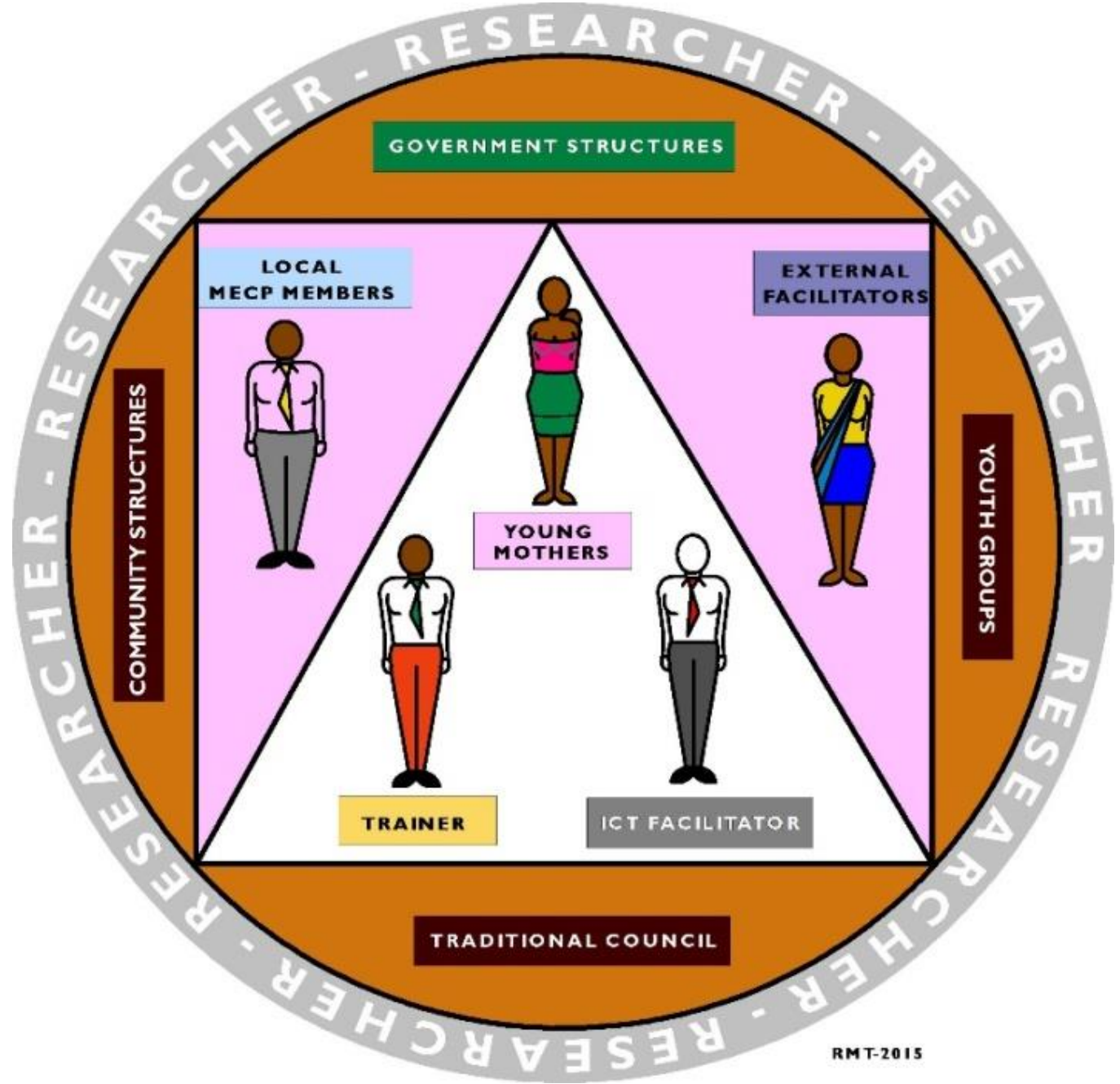

The study identified how the role and visibility of the YMs changed as the course progressed over time (see Figure 3). It points to champions acting as catalysts to enable YMs and their older women mentors to fill different roles in the development and delivery of community-based BAE. 
Figure 3

Models Indicating (a) Actual and (b) Predicted (Future) Core Contributors in the CBPAR Intervention With YMs at the Centre, and Future Roles Developing Over Time (source: Thompson, 2016)

(a)

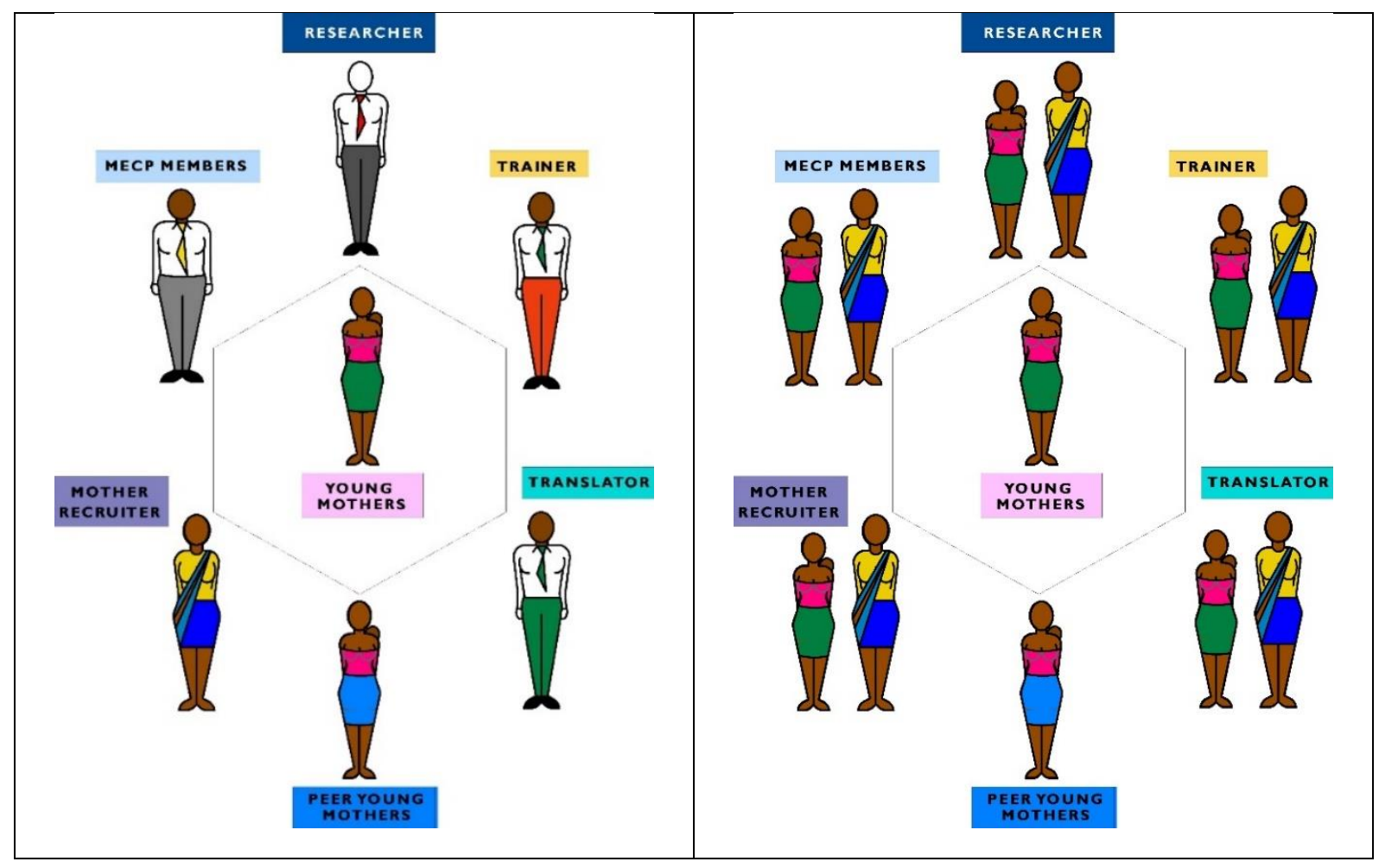

\section{Data Analysis}

When analysing the data gathered using different tools and sources over a period of more than six months, it was necessary to retain focus on the original research questions. Additional sub-questions were formulated to assist with the interpretation process.

\section{Coding and Organising the Results}

A semi-grounded approach was used to analyse the qualitative data. Line-by-line reading and systematic coding was done using Strauss and Corbin's (1994) grounded techniques of coding, categorising, listing, memoing, and diagramming to structure the data and extract themes. The study was not fully grounded. It was guided by research questions that steered the initial thematic interpretation of the data. This relates to Saldaña's (2012) "less theory bound" analytical approach, which accommodates multiple data sources.

Organisation of the transcripts, coded by participant and instrument, was initially done using Microsoft Excel spreadsheets. Direct quotes and strings of conversations from WhatsApp and email were then transferred to NVivo 10 software for organisation and coding using nodes and sub-nodes. Categories were recorded, tabulated, refined, and cross-referenced to extract common themes identified in NVivo 10. Word frequency and data tabling tools were used to compare and triangulate dialogues to identify common chronological threads from different participants. 
As themes emerged, diagrammatic representations or graphical visual summaries were used to present the findings in a more comprehensible way. A stock of coded images was created (Figure 4) and used to visualise the stages of implementation and the participants' role changes over time. This enabled feedback to be given to the participants and simplified the dissemination of the results (Figures 1, 2, and 3).

Figure 4

Stock Images Representing Participants in the Form of a Key (source: Thompson, 2016)

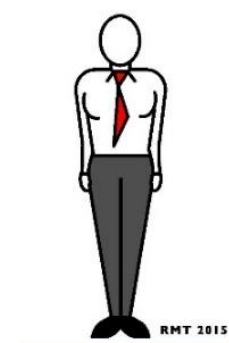

RESEARCHER

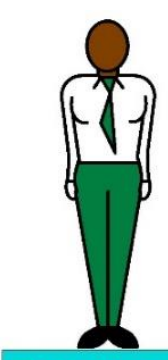

TRANSLATOR FACILITATOR

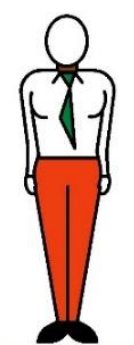

COURSE TRAINER

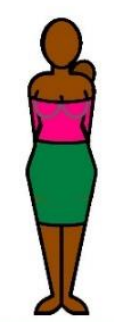

YOUNG MOTHERS
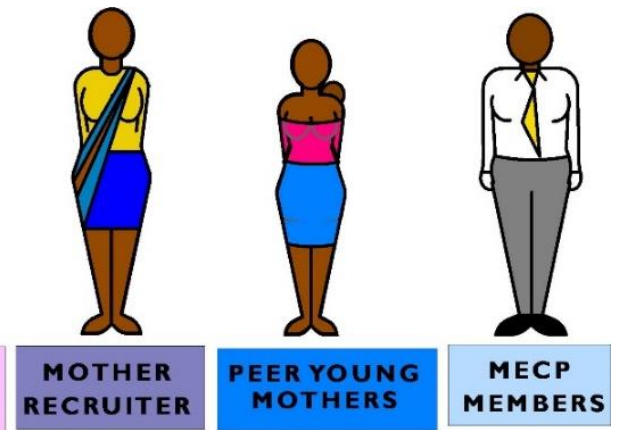

Stock images representing participants were created to develop a form of visual coding which could be deployed in different diagrams (see Figures 2, 3, and 4).

Photographs (such as Image 2) were also used by the trainers to report to the researcher and to document progress in setting up systems and managing the classes at the location. These were shared via email or WhatsApp at key stages during the study.

\section{Image 2}

$\mathrm{YMs}^{2}{ }^{2}$ ICT Lesson With XiTsonga-Speaking ICT Trainer (source: Thompson, 2016)

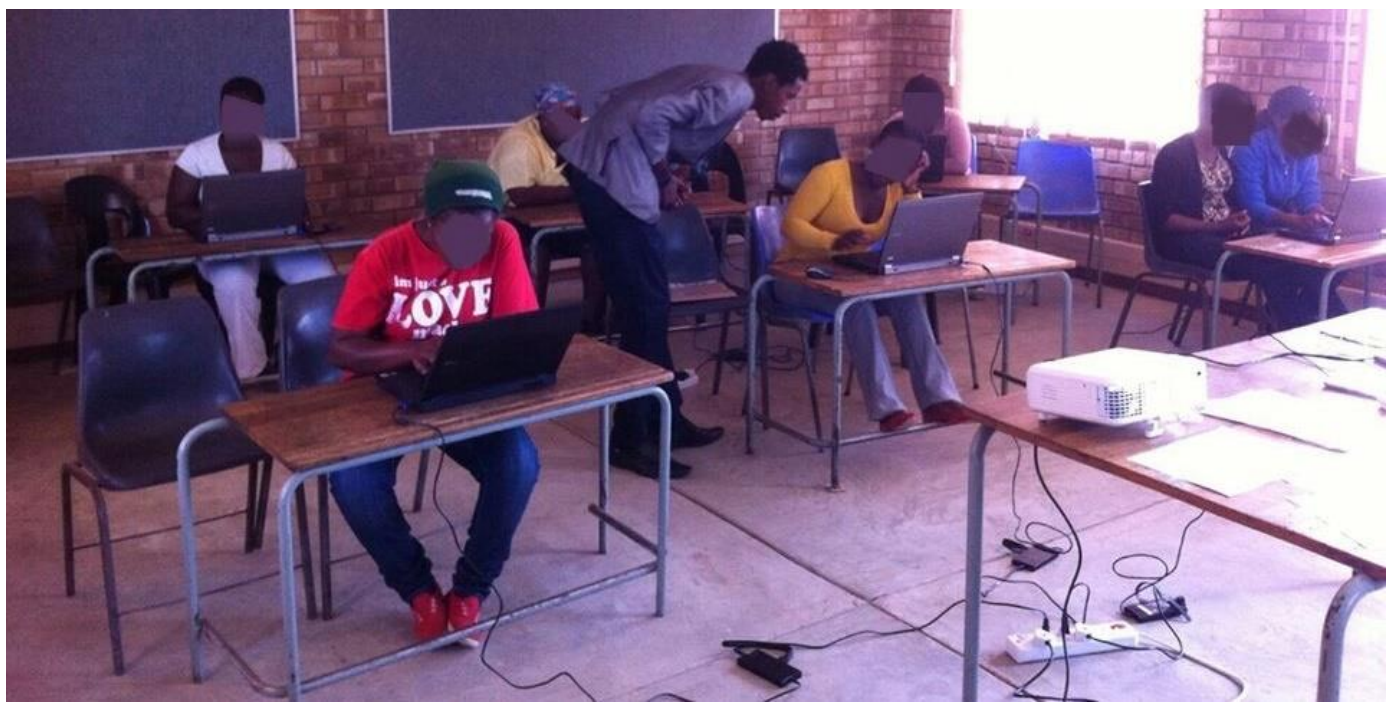

\footnotetext{
${ }^{2}$ The YMs' faces are blurred for anonymity.
} 
Methods used to validate the data included replaying the recordings to check for accuracy, having group discussions, and member checking the content of the surveys and evaluation forms with the participants at the conclusion of the interviews. Researcher, peer researcher, supervisor, and cosupervisor university-based weekly cohort meetings were used to further interrogate the themes, challenge researcher bias, and clarify interpretations of the data. Photographs were used as discussion points, and enabled interpretations of the data emerging from the sessions.

\section{Results}

\section{How Do We Use CBPAR as a Basis for a BAE Programme to Provide out-of-School YMs With Effective ICT and Nutrition Training in a Rural Area?}

The CBPAR approach aided implementation by empowering and strengthening the roles of active participants. The analysis showed that building on prior relationships helped to establish a CoP. The latter, which supported the study, will also aid in sustaining programmes in the future.

\section{How Can a CoP be Established to Design and Implement an ICT Training Course that Includes BAE Nutrition Education?}

With Respect to Design

Collaborative planning of the course started at a workshop attended by potential trainers, YMs, older women, and MECP and traditional council office representatives. They discussed course content, its value to the community, and course practicalities. A workshop format was chosen to create an adult forum in which the YMs were treated as equals. The six YMs who attended responded enthusiastically, recruited additional YMs, and suggested a suitable time and location for the course.

YM2: Because I will like to help others who [are] at home like young mothers to take good care of themselves.

The ICT part of the course followed a simplified version of existing computer training formats. Course content was designed by the researcher collaboratively with the German volunteer, UKZN supervisors, and the locally trained ICT graduate. The inclusion of nutritional data in the ICT course was identified as a chosen context in the initial YMs' workshop. They reported that this method of learning ICT skills was more interesting than repeating standard ICT exercises.

YM9: Because it helps me with communication and [to] learn more about living health[y] and be safe for you and your baby.

The design of such a course required active collaboration between trainer, technical facilitator, host school, YMs, village traditional office, and researcher at different stages. The course design started with a standard end-user computing course as a skeleton. Contextual nutritional examples were used to educate YMs and introduce ICT skills in a less formal manner. The final course evolved into a hybrid simplified ICT beginners' course with more locally sourced nutritional examples, for example, "blackjack" smoked beans, leaves, okra, spinach, ground nuts, and so forth. The YMs endorsed this approach in their feedback and reported that they would be comfortable passing on this knowledge, using their new ICT skills.

Adult education was identified as a communicative space for uniting people often isolated by their social circumstances. By meeting and working together under a programme of self-improvement, the YMs rapidly formed a CoP, which helped them overcome their fears and prejudices. The champions 
emerged at the project's inception. They remained a constant presence and helped to inspire more isolated members of the community to come forward.

The CoP encouraged flexibility in development and delivery of the course. Shared dialogues allowed for the emergence of valuable insights into village life and the lives of the YMs. They also provided evidence of the reciprocal notion of "giving back" to the community (Diver \& Higgins, 2014). The YMs emerged as a complex group sharing diverse lived experiences, motivations, and strengths. The course enabled champions who displayed leadership traits to emerge organically: promoting activities, encouraging others, speaking on behalf of the group, and offering their services to promote community development.

\section{With Respect to Implementation}

Data from the preliminary stage, which included meeting transcripts, letters, email records, and WhatsApp conversations, revealed that the establishment of the course was not instantaneous but the result of interrelated communications. Participants who facilitated and resourced the course came from both within and outside the community.

The group was taught in a relaxed informal manner, which acted as a catalyst for them to study and improve their social networks. This was partly due to the collaborative relationship developed between the local and volunteer trainers, who switched training and technical support roles early on:

YM-Facilitator: I am foreign. They are more or less afraid [of] me. They are much more open to [YM-Trainer]. That shows that teachers for these people here need to be people from here.

Implementation of the course required technical ingenuity from the trainer and facilitator working on a small budget. Successful delivery of the training was mostly achieved through the cooperation of the trainer/facilitators, host school, and YMs. Some financial and logistical support was provided by external sponsors and local structures. The YMs supported the implementation by promoting early classes to other YMs, attending regularly, and providing timeous critical feedback that influenced subsequent lessons. Their appreciation of the opportunity to learn was expressed in many ways. This had a positive motivational effect on trainers and helped sustain them through the course with limited resources.

Committed on-location volunteer trainers/facilitators, supported by mobile communication tools, made it possible for live action to be studied. The wider community aided facilitation by assisting in recruitment, providing childcare, and sourcing an alternative training venue.

Issues related to practice, and systems to enable practice, were discussed in communications throughout the process. These revealed how community-based BAE can empower individuals within the constraints of their social setting to challenge traditional structures. By the end of the course, a number of individuals emerged as champions-more than just graduates of an informal course.

The results from the study indicated a considerable need for BAE opportunities for YMs in rural communities of South Africa. The combined ICT and BAE nutrition course was well attended from the outset. However, attendance increased over the 6-week period as it was promoted by the YMs through informal networks. The YM champions were pivotal in making the course a success, using these networks to recruit other YMs. These networks operated more efficiently than planned methods of promoting and disseminating information involving traditional council administration. 
YM-Trainer: I spoke to one of the girls after the course this evening ... She wanted to bring other people. I told her ... she could but she would have to get them up to speed if they missed the first few classes.

\section{How Can Community-Based ICT and Nutrition Training Courses for YMs Be Implemented in Rural Resource-Limited Settings Such That They Are Sustainable?}

To follow or repeat such a process requires careful planning, regular communication between participants, and a willingness to adapt to a changing and unpredictable environment. Developing an understanding of local customs and behaviour through reconnaissance is necessary to build trust and create momentum for projects like this one. Sustaining such courses beyond the first trials requires investment of time and resources from providers, YMs, and village communities. Good record keeping, perseverance, and a willingness to acknowledge and learn from mistakes assist in sustaining projects of this scale.

The evolution of the group was significant in that it brought to the fore young women with qualities that one would associate with leadership and entrepreneurship. The leaders in the group recognised that the contextualised approach could be applied to learning other life skills, for example, childcare, sexual health, and financial management:

YM2: The food that we eat-fruits and vegetable-when pregnant, you need to know the food to eat [and] how to breastfeed children.

YM9: To teach young mothers how to prevent themselves from [contracting] HIV and STDs.

\section{How Can Further Constructive Interaction Be Stimulated as Part of Establishing a Process of Continual Improvement Through Direct Engagement?}

Mobile technologies, such as WhatsApp Messenger, assist greatly when working with remote communities where resources for communication via computer email and conferencing are limited. Mobile devices can help to stimulate and maintain communications to sustain relationships at a distance. The relationships formed in such projects can be fleeting and fragile. It is important to return to the location, acknowledge the value of participants' contributions, and listen to feedback. Interviews and focus groups can provide formal data but sometimes the casual, unrecorded conversations have more lasting value. For example, the post-workshop meeting we had at our village home with a small group of YMs proved vital in promoting the course further. We were not aware at the time that these were $\mathrm{YM}$ champions in the making.

Team teaching by the local trainer and a volunteer specialist gave the course a quality that empowered the YMs to reveal its shortcomings and limitations. Emergent leaders communicated the group's needs to the trainers. For example, ICT and BAE classes for young fathers in a separate class:

YM9: I wanted the man to know more about nutrition and learn to stay healthy.

YM5: It is nice to learn as ladies on our own.

They organically adopted the role of peer tutors offering help to YMs after class. In doing so, they recognised their own potential as future trainers:

YM4: We have a discussion after the lesson to know exactly about our young mothers.

YM9: We communicate and share some examples. 
Initially, classes were to be taught solely in English with resources stored in accessible desktop folders on each laptop computer. After two trial classes-one for Grade 12 learners and one for educators from the high school-the trainers switched roles. The experienced German volunteer became the classroom technician, while the locally trained youth became the trainer. Switching from teaching solely in English to conversational XiTsonga and English technical vocabulary significantly improved the course for those with limited listening and comprehension ability.

YM-Trainer: I was explaining the questions in English and furthermore in XiTsonga. Some answered in English and some answered in XiTsonga. It's good in terms of interacting with them. In the future, we can show that they are making progress.

This shift was accepted as part of a continual improvement process. It also fostered understanding and enjoyment, as noted in the excerpt below:

YM2: Because he help[s] us where we don't understand and he is respectful.

\section{Discussion}

The different types of champions were observed in terms of their participation and how they influenced the five CBPAR phases of the intervention. The results confirmed assumptions relating to existing theories on CoP (Lave, 1991; Wenger, 1998) and the reciprocity that is central to CBPAR (Maiter et al., 2008). The results also revealed a transient form of champion who can influence events over a short period of time and inspire others to be more present and durable as future champions.

Dialogues and interviews indicated that a number of factors motivated particular YMs to take on extra responsibility within the BAE setting to become champions of the course.

Although initially invited to attend the course's promotional workshop by older, more mature women, the YMs' decision to attend was a personal choice. Attendance at briefing meetings and course sessions was driven by personal motives, as stated in the interviews and feedback forms. These included potential career progression, desire to meet other YMs to share experiences in a neutral setting, and alleviating boredom and loneliness as unmarried mothers. This experience is not confined to rural African YMs. Similar experiences are reported in Vincent's (2016) study of YMs in the UK.

Leaders, or champions in the group, showed understanding of the value of community $B A E$, encouraging peers to attend training after assessing initial sessions themselves. By recruiting others, they showed leadership and community spirit. This sharing attitude may have grown out of necessity to maintain peer support networks in an under-resourced rural village.

Studies of feminine leadership (Batliwala, 2010) showed that the types of leadership adopted by women are not necessarily motivated by desire for power or personal gain. Understanding that development of the community has wide public benefit is a strong motivation. Many stressed that improving village infrastructure was a necessity. YMs in this study expressed the desire to improve their lives and find employment. The leaders had clearer personal motives. They demonstrated more empathy, showing greater willingness to share and help weaker students during and after lessons.

Suggestions for sustaining the course indicated that some had higher motives. Their aspiration to help sustain the training intervention at the MECP venue indicated their desire to be part of sustainable change in their community and to improve the plight of women. This is evident in their beginning to "claim leadership" (Batliwala, 2010, p. 18) by taking an active role in resourcing future courses from 
the "bottom up" (Murray \& Rudolph, 2019, p. 29). "As traditional state responsibilities are increasingly privatized, or outsourced, reliance on women's volunteerism has increased" (Strolovitch \& TownsendBell, 2013, p. 378).

The MECP was established by a woman and was promoted as a "democratic, legitimate and accountable" space (Batliwala, 2010, p. 18). The YMs were rightly keen to stake a claim to develop the MECP centre for BAE. Their motivation to work showed independence and a readiness to overcome a patriarchal environment where unrewarded labour is often delivered by women (Joachim, 2013).

The use of ICT and BAE nutrition training acted as a vessel for the CBPAR study. The YMs saw technology as a route to future employment and as an opportunity for further study. Receiving the ICT-BAE nutrition course free, they did not bear the cost of training but were aware of the value of continuing study in relation to their limited income. The participants also appreciated that computer and cellular technology could empower improved access to resources.

\section{Conclusion}

Following a CBPAR approach in monitoring the implementation of the YMs' ICT-BAE nutrition course enabled appreciation of the YMs' lives and ambitions in a rural village. This reflects successes reported globally in community-based rural development (Castleden \& Garvin, 2008; Tobias et al., 2013). With limited published research on CBPAR used for ICT training in rural communities, there is little recording of the experience of YMs outside school interventions (Chase, 2017). It is hoped that this study will contribute to the body of knowledge-enabling YMs to defeat poverty as active participants without losing their cultural connections (Genuis et al., 2015).

All AR involves risk taking. Relying on volunteer trainers to gather data and deliver training could have upset this study. The collection of significant data was largely trusted to these volunteers. Thankfully, the trainer and facilitator collaborated to provide valuable insights through regular feedback sessions. Regular briefing via WhatsApp and encouragement online contributed to their positive motivation (Gerber et al., 2017). Their obvious enjoyment in participation enhanced their sharing of the experience.

This study demonstrated the feasibility of implementing an effective training course for a marginalised group of YMs in a rural setting, using few resources. With limited funding, relying on the generosity of volunteers, it was not feasible to maintain the course. However, ICT resources were secured for future use in the MECP venue as a BAE venue. Champions from the group of YMs could fill the roles required to sustain the MECP and they were willing to learn to become future trainers. To sustain a training programme requires funding for local training of staff, administrative staff, technical maintenance, site maintenance, and security.

The CBPAR study revealed that single-sex BAE courses can bring YMs together in "collaborative spaces" and consider new social roles and more humane forms of living (Kemmis et al., 2014, p. 12). The YMs' class created their own forum and support systems within the class in which they were free to discuss their lives and reflect on appropriate careers to pursue.

Using nutrition as a teaching context for ICT exercises, YMs completed repetitive tasks to learn basic ICT skills. These included typing text, creating tables, organising lists, and manipulating images. The discussions based on the nutrition-based content empowered some to seek additional nutritional knowledge for better childcare. The adult learning space gave YMs confidence to assert themselves and raise personal issues relating to sexual health and relationships. 
There are many definitions of champion in the literature. However, Howell and Shea's (2001, p. 15) definition of "champion behaviour" as an "expression of confidence in the innovation, involving and motivating others" lends itself well to the champions who emerged in this study. The leaders in the group showed courage and willingness to overcome local prejudice to improve their education (Nkani \& Bhana, 2016).

Defining what makes a champion, and the traits to look for, is difficult in supporting the development of women leaders (Batliwala, 2010). Observing practice and cultivating young women's post-school development in adult education classes is a valuable research approach. Researching with YMs in a comfortable safe setting, allied with local support networks, cultivates communicative spaces where learning and self-expression coexist (Kemmis et al., 2014). Champions lose their inhibitions and express themselves more freely in the company of their peers. Emergent community leaders from YM groups need such spaces to develop. Developing leadership skills - or life skills-within a peer group is easier than working alone. Providing such opportunities in rural communities is a challenge but not impossible.

\section{Plagiarism Statement}

The authors would like to state that this article was developed from a short paper presentation first given at the 27th annual conference of the South African Association for Research in Mathematics, Science and Technology Education (SAARMSTE) conference, Durban, 15-17 January 2019. The paper was not taken to full publication and is accessible in a compilation of abstracts and short papers produced by the conference organisers.

\section{References}

Balazs, C. L., \& Morello-Frosch, R. (2013). The three Rs: How community-based participatory research strengthens the rigor, relevance, and reach of science. Environmental Justice, 6(1), 9-16. https://doi.org/10.1089/env.2012.0017

Balfour, R. J., Mitchell, C., \& Moletsane, R. (2011). Understanding rurality in the troubling context: Prospects and challenges. In F. Islam, C. Mitchell, N. de Lange, R. J. Balfour, \& M. Combrinck (Eds.), Partnerships for hope: A school-university collaboration for educational change in rural South Africa (pp. 23-40). Edwin Mellen.

Batliwala, S. (2010). Feminist leadership for social transformation: Clearing the conceptual cloud. Creating Resources for Empowerment in Action (CREA). https://www.uc.edu/content/dam/uc/ucwc/docs/CREA.pdf

Castleden, H., \& Garvin, T. (2008). Modifying photovoice for community-based participatory Indigenous research. Social Science \& Medicine, 66(6), 1393-1405. https://doi.org/10.1016/i.socscimed.2007.11.030

Chase, E. (2017). Beyond the diploma: Dimensions of success for teenage mothers in high school. Educational Review, 69(4), 506-522. https://doi.org/10.1080/00131911.2016.1247782

Cooperrider, D., Whitney, D. D., Stavros, J. M., \& Stavros, J. (2008). The appreciative inquiry handbook: For leaders of change. Berrett-Koehler.

Cuervo, H. (2016). Understanding social justice in rural education. Palgrave Macmillan.

Diver, S. W., \& Higgins, M. N. (2014). Giving back through collaborative research: Towards a practice of dynamic reciprocity. Journal of Research Practice, 10(2), 1-13. http://irp.icaap.org/index.php/irp/article/view/415/401 
Fredman, S., Kuosmanen, J., \& Campbell, M. (2016). Transformative equality: Making the sustainable development goals work for women. Ethics \& International Affairs, 30(2), 177-187. https://doi.org/10.1017/S089267941600006X

Genuis, S., Willows, N., Nation, A. F., \& Jardine, C. (2015). Through the lens of our cameras: Children's lived experience with food security in a Canadian Indigenous community. Child: Care, Health and Development, 41(4), 600-610. https://doi.org/10.1111/cch.12182

Gerber, H. R., Abrams, S. S., Curwood, J. S., \& Magnifico, A. M. (2017). Conducting qualitative research of learning in online spaces. SAGE.

Habermas, J. (1987). Theory of communicative action, volume II. Lifeworld and System: A critique of functional reason (trans. T. McCarthy). Beacon.

Howell, J. M., \& Shea, C. M. (2001). Individual differences, environmental scanning, innovation framing, and champion behavior: Key predictors of project performance. Journal of Product Innovation Management. 18(1), 15-27. https://doi.org/10.1111/1540-5885.1810015

Jernigan, V. B. B., Jacob, T., Team, T. C. R., \& Styne, D. (2015). The adaptation and implementation of a community-based participatory research curriculum to build tribal research capacity. American Journal of Public Health, 105(S3), 424-432. https://doi.org/10.2105/AJPH.2015.302674

Joachim, J. (2013). Local-global-local: Women's global organizing. In G. Waylen, J. Kantola, \& S. L. Weldon (Eds.), The Oxford handbook of gender and politics (pp. 462-484). Oxford University Press.

Kaukko, M. (2016). The P, A and R of participatory action research with unaccompanied girls. Educational Action Research, 24(2), 177-193. https://doi.org/10.1080/09650792.2015.1060159

Kemmis, S. (2009). Action research as a practice-based practice, Educational Action Research, 17(3), 463-474. https://doi.org/10.1080/09650790903093284

Kemmis, S., McTaggart, R., \& Nixon, R. (2014). The action research planner: Doing critical participatory action research. Springer Science \& Business Media.

Kindon, S., Pain, R., \& Kesby, M. (2007). Participatory action research approaches and methods: Connecting people, participation and place (vol. 22). Routledge.

Lave, J. (1991). Situating learning in communities of practice. In L. B. Resnick, J. M. Levine, \& S. D. Teasley (Eds.), Perspectives on socially shared cognition (pp. 63-82). APA.

Lewin, K. (1951). Problems of research in social psychology. In D. Cartwright (Ed.), Field theory in social science: Selected theoretical papers (pp. 155-169). Harper.

Maiter, S., Simich, L., Jacobson, N., \& Wise, J. (2008). Reciprocity: An ethic for community-based participatory action research. Action Research, 6(3), 305-325. https://doi.org/10.1177/1476750307083720

Mckay, S. (2011). Participatory action research, community-based. In D. J. Christie (Ed.), The encyclopedia of peace psychology. https://doi.org/10.1002/9780470672532.wbepp186

McTaggart, R. (2002). The role of the scholar in action research. In M. P. Wolfe \& C. R. Pryor (Eds.), The mission of the scholar: Research and Practice (pp. 1-16). Peter Lang.

Murray, J., \& Rudolph, N. (2019). Voices heard and lessons learnt: Exploring multiple knowledges and local participation in a community-based integrated early childhood development project in rural South Africa. Journal of Pedagogy, 10(1), 13-32. https://doi.org/10.2478/iped-2019-0001

Nkani, N., \& Bhana, D. (2016). Sexual and reproductive well-being of teenage mothers in a South African township school. South African Journal of Education, 36(2). https://doi.org/10.15700/saje.v36n2a1181 
Pain, R., Whitman, G., \& Milledge, D. (2011). Participatory action research toolkit. Durham University Press.

Saldaña, J. (2012). The coding manual for qualitative researchers. SAGE.

Schön, D. (1987). Educating the reflective practitioner. Jossey-Bass.

Sikakane, J. (1977). A window on Soweto. International Defence and Aid Fund (IDAF).

Singh, S., \& Naicker, P. (2019). Development of resilience in teenage mothers within contextual realities of poor rural South Africa. Journal of Poverty, 23(7), 559-575. https://doi.org/10.1080/10875549.2019.1616038

Statistics South Africa. (2017). Poverty trends in South Africa: An examination of absolute poverty between 2006 and 2015. https://www.statssa.gov.za/publications/Report-03-10-06/Report-0310-062015.pdf

Strauss, A. L., \& Corbin, J. (1994). Grounded theory methodology. In N. Denzin \& Y. Lincoln (Eds.), Handbook of qualitative research (pp. 273-285). SAGE.

Strolovitch, D. Z., \& Townsend-Bell, E. (2013). Sex, gender and society: International varieties of civil society. In G. Waylen, J. Kantola, \& S. L. Weldon (Eds.), The Oxford handbook of gender and politics (pp. 374-378). Oxford University Press.

Thompson, R. M. (2016). Implementation of an integrated ICT and BAE course for young mothers using CBPAR in Limpopo [Unpublished master's dissertation]. University of KwaZulu-Natal.

Tobias, J. K., Richmond, C. A., \& Luginaah, I. (2013). Community-based participatory research (CBPR) with indigenous communities: Producing respectful and reciprocal research. Journal of Empirical Research on Human Research Ethics, 8(2), 129-140. https://doi.org/10.1525/jer.2013.8.2.129

Trahar, S. Timmis, S. Lucas, L., \& Naidoo, K. (2020) Rurality and access to higher education. Compare: A Journal of Comparative and International Education, 50(7)929-942. doi:10.1080/03057925.2020.1810895

United Nations. (2020). The sustainable development goals report 2020. https://doi.org/10.18356/214e6642-en

Vincent, K. (2016). "It's the best thing I've done in a long while": Teenage mothers' experiences of educational alternatives. Critical Studies in Education, 57(1), 55-69. https://doi.org/10.1080/17508487.2016.1123167

Wenger, E. (1998). Communities of practice: Learning as a social system. The Systems Thinker, 9(5), 23. https://thesystemsthinker.com/communities-of-practice-learning-as-a-social-system/ 